\title{
Optimization for Reducing Warpage in Injection Moulding
}

\author{
P. Vamsi Krishna Pratyush $\mathrm{Kar}^{2}$ and G. Rajesh Babu ${ }^{3}$ \\ ${ }^{1,2}$ Department of Mechanical Engineering, National Institute of Technology Warangal, India. \\ ${ }^{3}$ GE Power, Industrial Solutions, Hyderabad, India. \\ ${ }^{1}$ vamsikrishna@nitw.ac.in
}

\begin{abstract}
Injection molding is a standout technique utilized for the fabrication of thermoplastic parts in industry due to short product cycles, high part quality, good mechanical properties and low cost for large scale manufacturing. In molded case circuit breaker (MCCB), Trip-bar is one of the most critical components as safety is concerned which is manufactured by injection molding process. To get it manufactured within the specified warpage and deformities free, number of mold flow simulations is carried out using Creo-MoldFlow. The outcomes of the simulation are used to design the mold tool and the process parameters for injection molding are optimized. For process parameter optimization Taguchi based experimental design and ANOVA analysis is done. The objective of this work is to optimize the injection molding process parameters such as filling time, melt temperature and mold temperature to minimize the warpage. CAE flow simulation software is used to simulate the process and Grey Relational Analysis (GRA) is used to find out optimum process parameters.
\end{abstract}

\section{Key words: $M C C B$, Injection molding, Moldflow simulation}

\section{INTRODUCTION}

Tripbar is one of the most critical components of molded case circuit breakers. It trips the breaker when any of the poles experiences a high instantaneous current. Hence, it's very crucial for the circuit breaker as safety is concerned. The quality of tripbar produced by injection molding depends on the material, geometry, mold design and the process parameters. Simulation of plastic flow allows enhancement in mold design that leads to the creation of highest quality products. This analysis provides a virtual idea how the chosen material will fill a mold's cavity and indicates the potential areas of concern and should be conducted before the beginning of tooling production to optimize the process. This analysis is done using Mold Flow Analysis (MFA) software. B.Ozvelik et.al [1] worked on the minimization of the warpage and sink mark in terms of process parameters of the plastic parts having different rib cross-section and layout using Taguchi optimization method for polycarbonate materials. S.Tang et.al [2] fabricated a mold to produce a thin plate having dimension $120 \mathrm{~mm} \times 50 \mathrm{~mm} \times 1 \mathrm{~mm}$. The thin plate is used for warpage testing. The mold is fixed on the injection molding machine and it is set to produce the part. After the analysis on warpage, it showed that the effect of melt temperature is more on warpage. The finite element analysis of an injection molding process evaluates the component manufacturability at the early stage of the product development cycle without fabricating prototypes and reducing the experimental tests. Many researchers are also working on the injection molding process to optimize the process conditions for high product quality and increasing productivity.

The present work focuses on optimization of injection molding process considering cooling time, clamping force, residual shear stress and volumetric shrinkage and to obtain the suitable processing conditions. The optimized process conditions will be used for designing the mold tool.

Corresponding Author: P. Vamsi Krishna, Department of Mechanical Engineering, National Institute of Technology Warangal, India , NIT Warangal, India. +91-8332969371. 


\section{METHODOLOGY}

The numerical analyses are based on the 3-D Navier Strokes flow solver with governing equations for mass, momentum, and energy [3]. The generalized Hele-Shaw flow is assumed for flow analysis. Viscosity of

polymer melts varies with shear rate, pressure and temperature. Therefore, viscosity models should account for the variation with shear rate, pressure and temperature. Such viscosity models include Cross Exp and Cross WLF models [4]. Model constants implemented in the numerical simulations are summarized in Table 1.

Table 1. Cross WLF Viscosity Model Coefficient

\begin{tabular}{|c|c|c|}
\hline Constant & Values & Units \\
\hline $\mathrm{N}$ & 0.4924 & - \\
\hline $\mathrm{T}$ & 260000 & $\mathrm{~Pa}$ \\
\hline $\mathrm{D}_{1}$ & $2.9 \mathrm{e} 13$ & $\mathrm{~Pa}-\mathrm{sec}$ \\
\hline $\mathrm{D}_{2}$ & 323.15 & $\mathrm{~K}$ \\
\hline $\mathrm{D}_{3}$ & 0 & $\mathrm{~K} / \mathrm{Pa}$ \\
\hline $\mathrm{A}_{1}$ & 31.12 & - \\
\hline $\mathrm{A}_{2} *$ & 51.6 & $\mathrm{~K}$ \\
\hline
\end{tabular}

\section{RESULTS AND DISCUSSION}

A number of simulations are conducted using AutoDesk-MoldFlow which is based on hybrid finiteelement/finite difference method for solving pressure, flow and temperature fields. In order to reduce the time,
Taguchi based L9 orthogonal array is used. In this study, the process parameters ranges recommended from AutoDesk-MoldFlow are used and the ranges are provided in Table 2. Table 3 shows output responses, cooling time in sec, clamping force in Ton, Volumetric shrinkage in \% and shear stress in $\mathrm{MPa}$ for each simulation run. The process parameters chosen are injection time, mold temperature and melt temperature.

Table2. Process parameters with different levels

\begin{tabular}{|c|c|c|c|}
\hline Input parameters & Level 1 & Level 2 & Level 3 \\
\hline Mold temp $\left({ }^{0} \mathrm{C}\right)$ & 120 & 130 & 140 \\
\hline Melt Temp $\left({ }^{0} \mathrm{C}\right)$ & 250 & 270 & 290 \\
\hline Injection time (sec) & 2 & 2.5 & 3 \\
\hline
\end{tabular}

\subsection{Effect of Melt Temperature}

Figure.1 indicates the effect of melt temperature on cooling time, shear stress, clamping force and shrinkage. The cooling time shows an increment behavior with increase in melt temperature because of more heat transfer time from mold cavity to the surrounding. Residual shear stress and clamping force reduces as the flow of plastic is more uniform and obstruction less with increase in melt temperature. Shrinkage increases with increase in melt temperature as thick areas will take more time to solidify.

Table3. Input Conditions and output responses for individual simulation

\begin{tabular}{|c|c|c|c|c|c|c|c|}
\hline & \multicolumn{3}{|c|}{ Input variables } & \multicolumn{4}{c|}{ Output responses } \\
\hline $\begin{array}{c}\text { S. } \\
\text { No }\end{array}$ & $\begin{array}{c}\text { Injection } \\
\text { Time } \\
(\mathrm{Sec})\end{array}$ & $\begin{array}{c}\text { Mold } \\
\text { Temperature } \\
\left({ }^{\circ} \mathrm{C}\right)\end{array}$ & $\begin{array}{c}\text { Melt } \\
\text { Temperature } \\
\left({ }^{\circ} \mathrm{C}\right)\end{array}$ & $\begin{array}{c}\text { Cooling } \\
\text { time }(\mathrm{sec})\end{array}$ & $\begin{array}{c}\text { Clamping } \\
\text { Force (Ton) }\end{array}$ & $\begin{array}{c}\text { Volumetric } \\
\text { Shrinkage }(\%)\end{array}$ & $\begin{array}{c}\text { Shear } \\
\text { Stress } \\
(\mathrm{MPa})\end{array}$ \\
\hline 1 & 2 & 120 & 250 & 86.704 & 10.727 & 7.221 & 2.871 \\
\hline 2 & 2 & 130 & 270 & 104.833 & 4.175 & 7.903 & 1.372 \\
\hline 3 & 2 & 140 & 290 & 123.064 & 1.806 & 8.644 & 0.454 \\
\hline 4 & 2.5 & 120 & 270 & 99.284 & 3.372 & 7.895 & 1.184 \\
\hline 5 & 2.5 & 130 & 290 & 115.66 & 1.61 & 8.628 & 0.472 \\
\hline 6 & 2.5 & 140 & 250 & 97.484 & 9.615 & 7.189 & 2.601 \\
\hline 7 & 3 & 120 & 290 & 109.534 & 1.533 & 8.611 & 0.499 \\
\hline 8 & 3 & 130 & 250 & 91.469 & 8.87 & 7.151 & 2.277 \\
\hline 9 & 3 & 140 & 270 & 111.643 & 3.365 & 7.079 & 1.058 \\
\hline
\end{tabular}




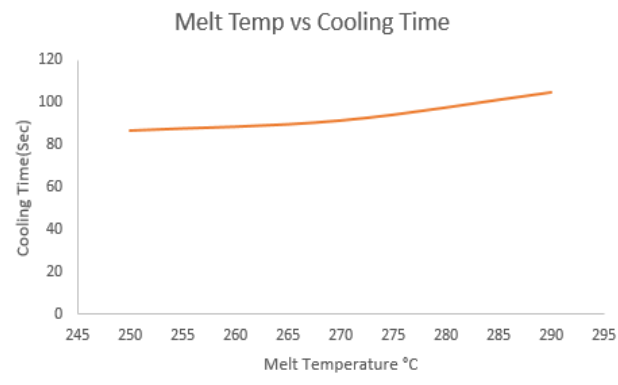

[A]

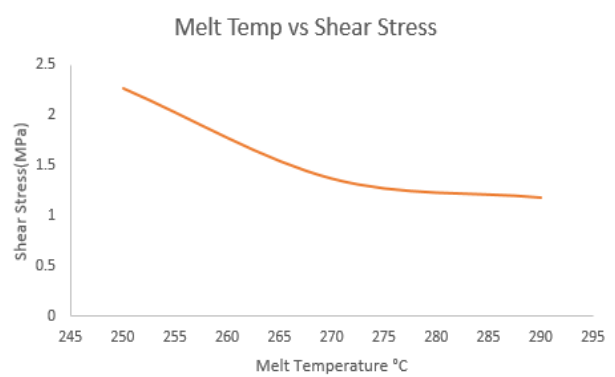

[B]

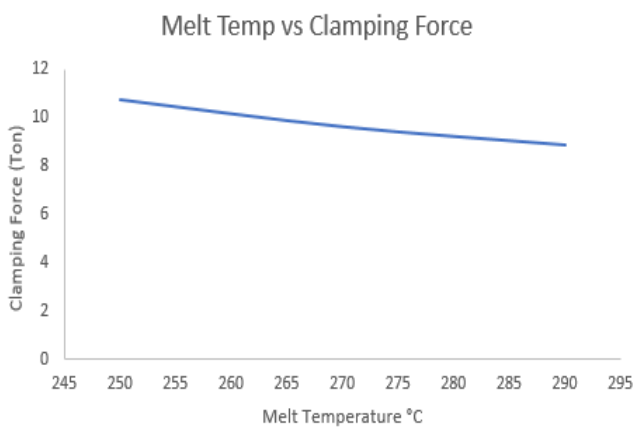

[C]

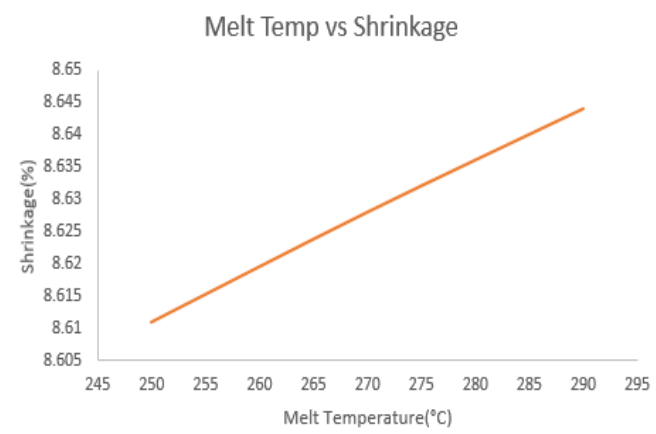

[D]

Figure 1. Effect of Melt Temperature [A] Cooling Time, [B] Shear Stress, [C] Clamping Force, [D] Shrinkage

\subsection{Effect of Mold Temperature}

The figure. 2 shows the effect of mold temperature on responses as shear stress, clamping force, cooling time and shrinkage. It can be observed from the graph that, with increase in mold temperature the shear stress and clamping force values are getting reduced. Induced shear stress can be reduced if the plastic flows inside the cavity with less obstruction and friction. The mold temperature helps in reducing the cohesive force. Further, it is observed that the cooling time to reach the ejection and shrinkage temperature increases with increase in mold temperature. Thus for cooling, the heat transfer from melt to the water channels will be reduced by maintaining high mold temperature.

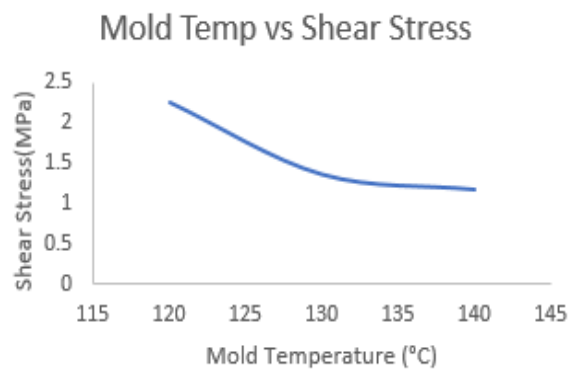

[A]

Mold Temp vs Clamping Force

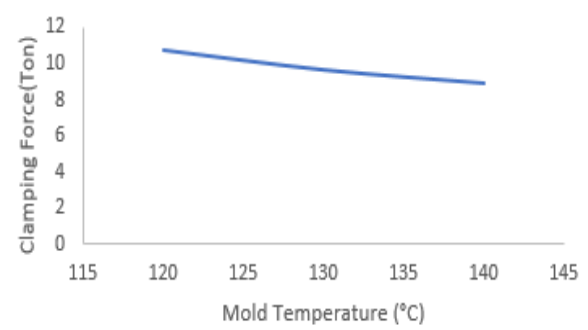

[B]

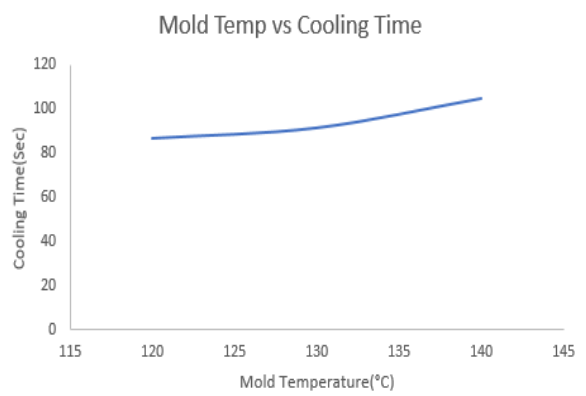

[C]

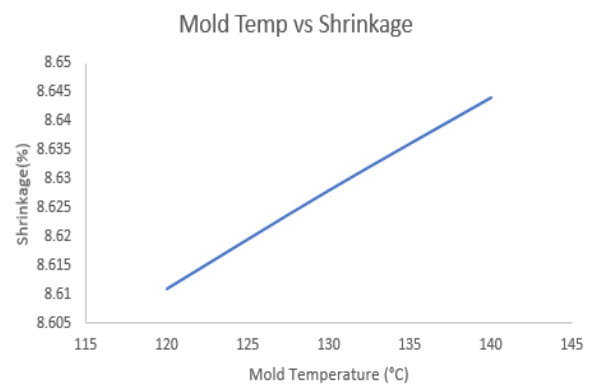

[D]

Figure 2. Effect of Mold Temperature [A] Shear Stress, [B] Clamping Force, [C] Cooling Time, [D] Shrinkage 


\subsection{Effect of Injection time}

The figure. 3 shows the effect of injection time on responses as cooling time, clamping Force, volumetric shrinkage and residual shear stress. It can be observed from the graph that, with increase in injection time the cooling time is getting reduced. The increase in injection time makes the injection pressure lower causing less friction and reducing the duration of cooling time. The clamping force experiences an incremental behavior with increasing injection time as high injection time indirectly lowers the melt temperature. The volumetric shrinkage decreases with increase in injection time due to the thick sections which takes more time to solidify. Residual shear stress increases as injection period is more, owing to the fact that, more injection period lowers the melt temperature making the flow less uniform and with increased resistance.

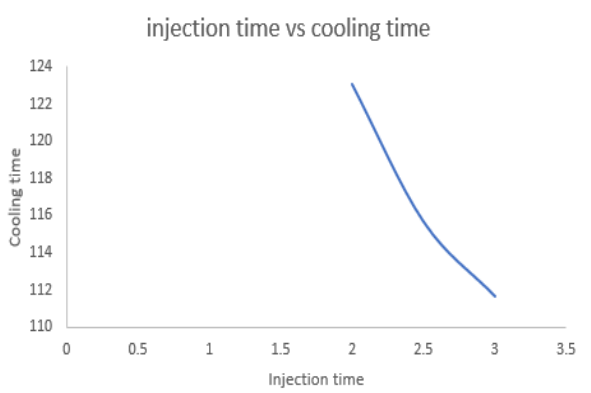

[A]

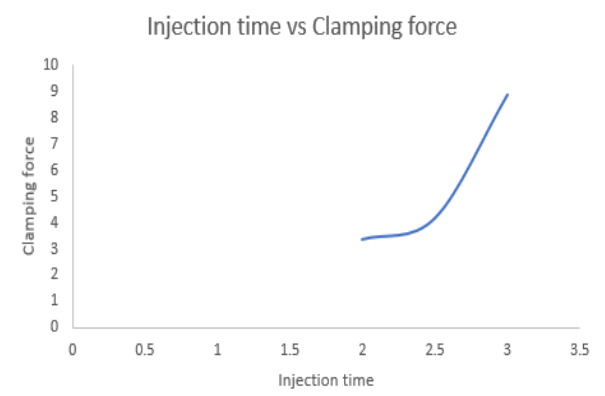

[B]

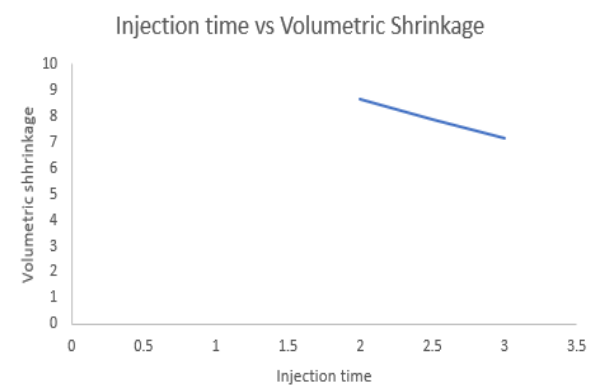

[C]

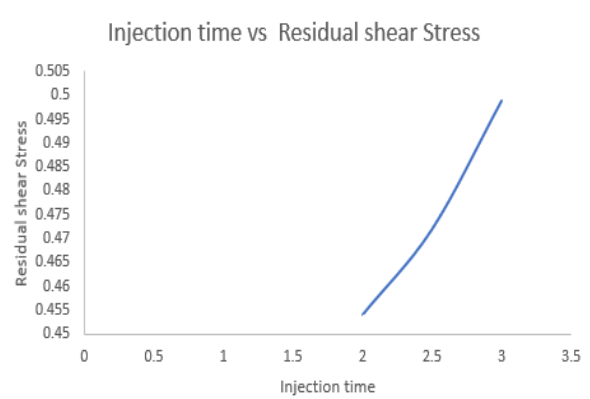

[D]

Figure 3. Effect of Injection time on [A] cooling time, [B] Clamping Force, [C]Volumetric Shrinkage, [D]Residual shear stress

\subsection{Clamping Force Analysis}

The effect of input parameters on clamping force is analyzed using Taguchi orthogonal experiment Design. Signal to noise ratio ( $\mathrm{S} / \mathrm{N}$ ratio) is calculated considering smaller is the better since our objective is to minimize the clamping force. The $\mathrm{S} / \mathrm{N}$ ratio is logarithmic transformation of the loss function, given as

$\frac{S}{N}=-10 \log _{10}\left[\frac{1}{n} \sum_{i}^{n} Y_{i}^{2}\right]$

The obtained clamping force value for different simulation runs is given in the table4. The influence of control parameters such as injection time, mold temperature and melt temperature have been analyzed using Minitab software.

Table4. Response Table S/N ratio for clamping force

\begin{tabular}{|c|c|c|c|}
\hline Level & Injection time & Mold temp & Melt temp \\
\hline 1 & -12.717 & -11.626 & -19.742 \\
\hline 2 & -11.451 & -11.836 & -11.17 \\
\hline 3 & -11.07 & -11.776 & -4.326 \\
\hline Delta & 1.648 & 0.21 & 15.417 \\
\hline Rank & 3 & 2 & 1 \\
\hline
\end{tabular}

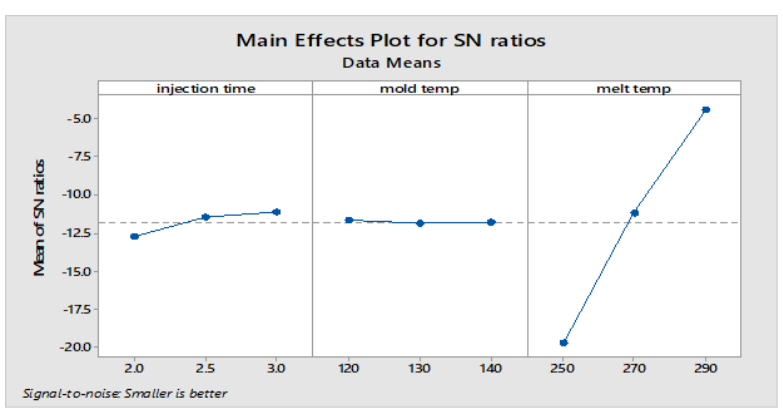

Figure 4 Main Effects plot for $\mathrm{S} / \mathrm{N}$ ratio for clamping force

The analysis of variance is employed to determine which control factors are affecting the response at which 
level. If the P-value obtained from ANOVA is less than the significance level (0.05), then that factor is considered to be statistically significant. The ANOVA analysis table is shown in table 5 .

Table 5. ANOVA table for clamping force

\begin{tabular}{|c|c|c|c|c|c|}
\hline Parameters & $\begin{array}{c}\text { Degree of } \\
\text { freedom }\end{array}$ & $\begin{array}{c}\text { Sum of } \\
\text { squares }\end{array}$ & $\begin{array}{c}\text { Mean of } \\
\text { square }\end{array}$ & F value & P-value \\
\hline Injection Time & 2 & 1.531 & 0.7654 & 3.05 & 0.247 \\
\hline Mold Temp & 2 & 0.188 & 0.0938 & 0.37 & 0.728 \\
\hline Melt Temp & 2 & 106.578 & 53.2889 & 212.64 & 0.005 \\
\hline Error & 2 & 0.501 & 0.2506 & & \\
\hline Total & 8 & 108.798 & & & \\
\hline
\end{tabular}

From the $\mathrm{S} / \mathrm{N}$ ration and ANOVA analysis we can conclude that for clamping force the main influential parameter is melt temperature and from the figure $4[\mathrm{C}]$ it is evident that with increase in melt temperature the clamping force reduces.

\subsection{Cooling time analysis}

Cycle time of a part in injection molding process is very important as the rate of production and the quality of the parts depend on it. The cycle time of a part can be reduced by reducing the cooling time. To understand the impact of various process parameters on cooling time, Taguchi based orthogonal experiments is used. $\mathrm{S} / \mathrm{N}$ ratio of "smaller the better" characteristics is considered. To support this analysis ANOVA is performed and results are tabulated in table 6 and table 7.

Table 6. Response Table S/N ratio for cooling time

\begin{tabular}{|c|c|c|c|}
\hline level & Injection time & Mold temp & Melt temp \\
\hline 1 & -40.20 & -39.82 & -39.25 \\
\hline 2 & -40.40 & -40.31 & -40.44 \\
\hline 3 & -40.41 & -40.87 & -41.31 \\
\hline Delta & .21 & 1.06 & 2.06 \\
\hline Rank & 3 & 2 & 1 \\
\hline
\end{tabular}

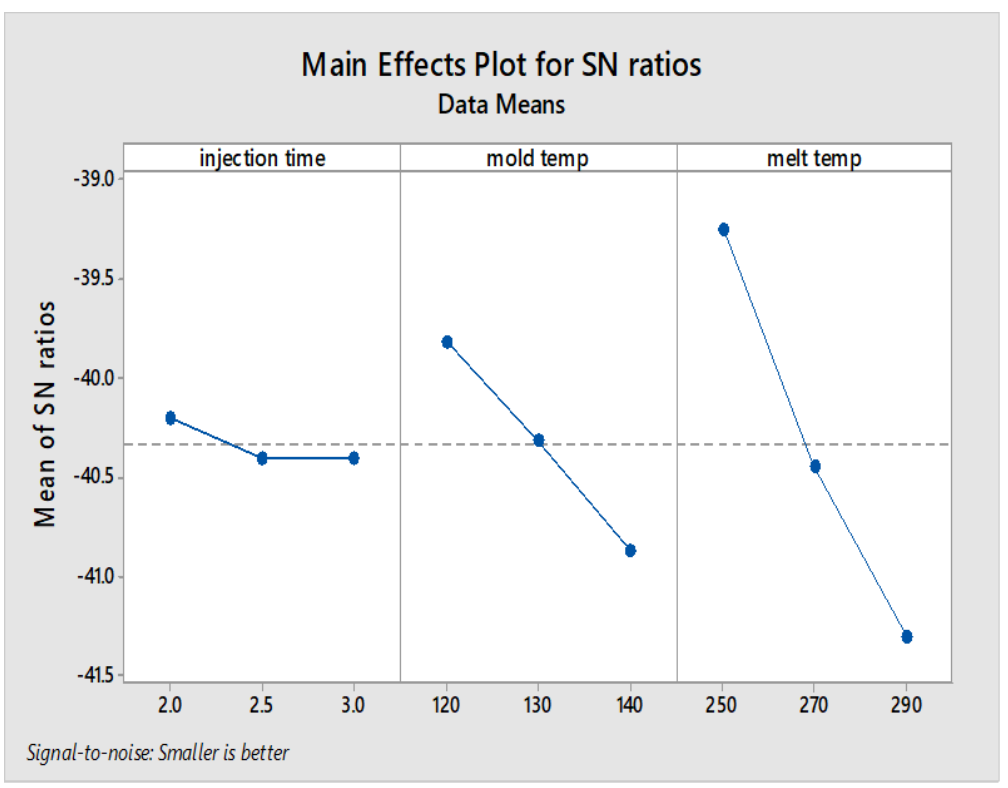

Figure 5. Main Effects plot for S/N ratio for cooling time 
Table 7. ANOVA table for cooling time

\begin{tabular}{|c|c|c|c|c|c|}
\hline Parameters & $\begin{array}{c}\text { Degree of } \\
\text { freedom }\end{array}$ & $\begin{array}{c}\text { Sum of } \\
\text { squares }\end{array}$ & $\begin{array}{c}\text { Mean of } \\
\text { square }\end{array}$ & F value & P-value \\
\hline Injection Time & 2 & 5.99 & 2.994 & 5.89 & .145 \\
\hline Mold Temp & 2 & 236.02 & 118.012 & 232.18 & .004 \\
\hline Melt Temp & 2 & 903.10 & 451.551 & 888.38 & .001 \\
\hline Error & 2 & 1.02 & 0.508 & & \\
\hline Total & 8 & 1146.13 & & & \\
\hline
\end{tabular}

From the results of $\mathrm{S} / \mathrm{N}$ ratio analysis and ANOVA, it is found that melt temperature is most influential followed by cooling time and mold temperature respectively. As the heat transfer occurs from molten plastic to the surrounding through the mold, higher the temperature, more is the cooling time.

\subsection{Volumetric Shrinkage Analysis}

Uncompensated shrinkage can lead to either shrink marks or voids in the interior of the mold. Controlling part shrinkage is important in part, mold and process designs particularly in applications requiring tight tolerances. To understand the impact of various process parameters on cooling time Taguchi based orthogonal experiments is used. S/N ratio of "smaller the better" characteristics is considered. To support this analysis ANOVA is performed and results are tabulated in table 9.

Table8. Response Table $\mathrm{S} / \mathrm{N}$ ratio for volumetric shrinkage

\begin{tabular}{|c|c|c|c|}
\hline level & Injection time & Mold temp & Melt temp \\
\hline 1 & -17.94 & -17.91 & -17.07 \\
\hline 2 & -17.94 & -17.93 & -17.95 \\
\hline 3 & -17.91 & -17.94 & -18.76 \\
\hline
\end{tabular}

\begin{tabular}{|c|c|c|c|}
\hline Delta & .03 & .03 & 1.69 \\
\hline Rank & 3 & 2 & 1 \\
\hline
\end{tabular}



Figure 6. Main Effects plot for $\mathrm{S} / \mathrm{N}$ ratio for Volumetric Shrinkage

From the S/N ratio and ANOVA analysis, it is observed that, the most influential factor is melt temperature and when it is at $290^{\circ} \mathrm{C}$, shrinkage is the highest. The possible reason can be the maximum heat transfer from the surface which results in the formation of frozen layer and causing core to shrink.

Table 9. ANOVA table for Volumetric Shrinkage

\begin{tabular}{|c|c|c|c|c|c|}
\hline Parameters & DOF & Sum of squares & Mean of square & F value & P-value \\
\hline Injection Time & 2 & 0.1801 & 0.09006 & 1.37 & 0.422 \\
\hline Mold Temp & 2 & 0.1399 & 0.06995 & 1.07 & 0.484 \\
\hline Melt Temp & 2 & 3.2720 & 1.63598 & 24.93 & 0.039 \\
\hline Error & 2 & 0.1313 & 0.06564 & & \\
\hline Total & 8 & 3.7233 & & & \\
\hline
\end{tabular}

\subsection{Residual Shear Stress Analysis}

Residual shear stress induces in the part during filling state in the cavity. If the viscosity of the material is not as required, it results in more shear stress generation. The residual stress affects the part functionality when being put into service. It can only be minimized in the process condition and controlling the process parameters. To understand the effects, Taguchi based experimental design, $\mathrm{S} / \mathrm{N}$ ratio calculation is done. To support the analysis, ANOVA is computed and results are tabulated in table 11 . 
Table10. Response Table S/N ratio for Residual Stresses

\begin{tabular}{|c|c|c|c|}
\hline Level & Injection time & Mold temp & Melt temp \\
\hline 1 & -4.67170 & -1.01013 & -6.79386 \\
\hline 2 & 3.13751 & 0.00909 & -1.38807 \\
\hline 3 & 1.66505 & 1.13190 & 8.31279 \\
\hline Delta & 7.80921 & 2.14203 & 15.10665 \\
\hline Rank & 2 & 3 & 1 \\
\hline
\end{tabular}

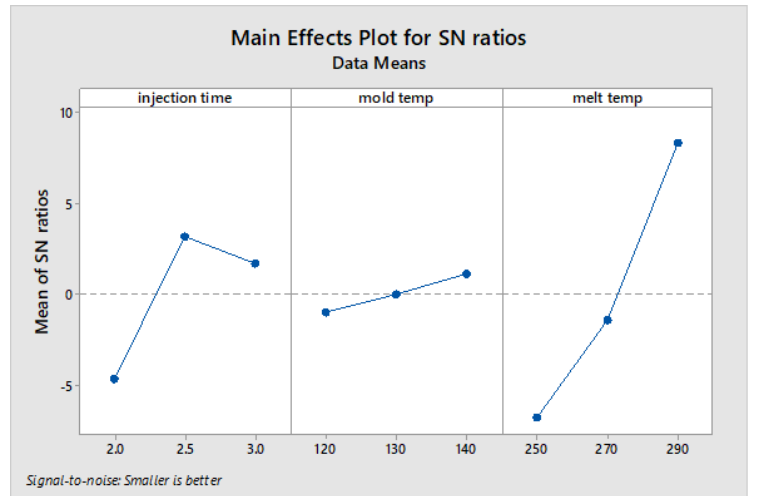

Figure 7. Main Effects plot for S/N ratio for Residual Stresses

Table11. ANOVA table for Residual Stresses

\begin{tabular}{|c|c|c|c|c|c|}
\hline Parameters & $\begin{array}{c}\text { Degree of } \\
\text { freedom }\end{array}$ & Sum of squares & $\begin{array}{c}\text { Mean of } \\
\text { square }\end{array}$ & F value & P-value \\
\hline Injection Time & 2 & 3.0316 & 1.5158 & 8.28 & 0.108 \\
\hline Mold Temp & 2 & 1.0871 & 0.5436 & 2.97 & 0.252 \\
\hline Melt Temp & 2 & 6.0675 & 3.0338 & 16.56 & 0.057 \\
\hline Error & 2 & 0.3663 & 0.1832 & & \\
\hline Total & 8 & 10.5525 & & & \\
\hline
\end{tabular}

From the above analysis it is seen that melt temperature is most influential in residual stresses as the lower value of melt temperature reduces the viscosity of the molten plastic. As viscosity reduces, the molten plastic finds it difficult to flow which induces stresses in the part.

\section{CONCLUSION}

Mold flow analysis is carried out for studying the flow behavior and defects. Some kind of relationship is established between parameters by using mold flow analysis. In injection molding process parameters play a vital role in deciding machine tonnage, cycle time, part warpage and residual shear stresses. So, optimization of process parameters is performed taking melt temperature, mold temperature and injection time as input. Taguchi based grey relational analysis is used for optimization. The following conclusions can be made from the mold flow analysis work-

- The optimal sets of process parameters as found out by Grey Relational Analysis is mold temperature of $140{ }^{\circ} \mathrm{C}$, melt temperature of $270{ }^{\circ} \mathrm{C}$ and injection time of $3 \mathrm{Sec}$.

- $\quad$ The effect of melt temperature on response is maximum followed by mold temperature and injection time.

Maximum efficiency of upwind and downwind Thai sail windmill model respectively was about $27 \%$ and $25 \%$ which was slightly different. Optimum pitch angle of both models was the same at 10 degrees. However, the downwind rotor was better choice for Thai sail windmill rather than the upwind rotor because although the downwind model gave efficiency less than the upwind model, it was merely small difference and it gave much more advantages, for example, it can be a passive yaw mechanism by itself for helping a rotor face perpendicularly to all wind directions and use only one pole, which can reduce construction cost and enhance the annual energy production.

\section{ACKNOWLEDGMENTS}

This work was supported by GE Power (Industrial Solutions), Hyderabad, who provided insight and expertise that greatly assisted the work.

\section{REFERENCES}

[1] B. Ozvelik and E. T, "Comparison of the warpage optimization in the plastic injection molding using ANOVA,Neural Network Model and Genetic Algorithim," Journal of Materials Processing Technology, vol. 171, pp. 437-445, 2006.

[2] S. Tang, Y. Tan and R. Samin, "The use of Taguchi methos in the design of plastic injection mold for reducing warpage," Journals of materials Processing Technology, vol. 28, pp. 418-426, 2007.

[3] H. Marton and B. Fawzi, "Sustainable injection moulding: The impact of materials selection and," Sustainable Materials and Technologies, vol. 5, pp. 1-8, 20 july 2015.

[4] T. A. Osswald and R. Natalie, Polymer Rheology, cincinnati: Hanser Publishers. 